\title{
On the Early Stage Isothermal Oxidation of APS CoNiCrAIY Coatings
}

\author{
G. Di Girolamo, M. Alfano, L. Pagnotta, A. Taurino, J. Zekonyte, and R.J.K. Wood
}

(Submitted February 28, 2011; in revised form November 10, 2011)

\begin{abstract}
The aim of this study is to analyze the evolution of microstructural and room temperature mechanical properties of air plasma sprayed (APS) CoNiCrAIY coatings before and after early stage high-temperature oxidation. To this purpose, selected samples were isothermally heat treated at $1110{ }^{\circ} \mathrm{C}$ for different durations. Phase analysis and oxide scale characterization were performed using $x$-ray diffraction. Morphological and microstructural features of as-sprayed and oxidized CoNiCrAIY coatings were analyzed by scanning electron microscopy and energy dispersive $x$-ray spectroscopy. After heat treatment, a duplex oxide scale, composed of an inner $\alpha-\mathrm{Al}_{2} \mathrm{O}_{3}$ layer and an outer spinel-type oxide layer, was observed on coating top-surface. The nanoindentation technique was employed to study the evolution of the mechanical properties. An increase in Young's modulus and hardness with increasing the aging time was observed, this effect was mainly addressed to the partial densification of coating microstructure.
\end{abstract}

Keywords coatings, heat resistant metals, thermal spray

\section{Introduction}

Ni-based hot section components of aircraft and land-based gas turbines typically operate in the presence of high temperature $\left(>900-1000{ }^{\circ} \mathrm{C}\right)$, high mechanical stresses and oxidizing environments. In addition, the presence of corrosive agents produces severe operating conditions thereby reducing the durability. To this purpose, the application of a protective coating on the surface of these components allows an increase in their lifetime. This reduces through life costs, fuel consumption and cooling air flow requirements as well as the emissions of $\mathrm{NO}_{x}$ and $\mathrm{CO}$ into the atmosphere.

A metal overlay coating, generally composed of a MCrAlY $(\mathrm{M}=\mathrm{Co}, \mathrm{Ni})$ alloy, is usually applied by thermal spraying in order to improve high-temperature oxidation and hot-corrosion resistance of metal substrate $(\operatorname{Ref} 1,2)$. It also plays a significant role on the durability of thermal barrier coatings (TBCs); indeed, a MCrAlY coating can be also employed as a bond coat in conjunction with an upper ceramic $\mathrm{TBC}$, to increase the operating temperature of turbine components $(\operatorname{Ref} 3)$.

During in-service high-temperature exposure, a thermally grown oxide (TGO) layer typically grows on the top-surface of

G. Di Girolamo, ENEA, UTTMATB, Brindisi Research Centre, Strada Statale 7 Appia, km 706, 72100 Brindisi, Italy and Department of Mechanical Engineering, University of Calabria, Ponte P. Bucci, Cubo 44C, 87036 Rende, CS, Italy; M. Alfano and L. Pagnotta, Department of Mechanical Engineering, University of Calabria, Ponte P. Bucci, Cubo 44C, 87036 Rende, CS, Italy; A. Taurino, Institute for Microelectronics and Microsystems, National Research Council, Via per Monteroni, 73100 Lecce, Italy; and J. Zekonyte and R.J.K. Wood, National Centre for Advanced Tribology (nCATS), University of Southampton, Southampton SO171BJ, UK. Contact e-mail: giovanni.digirolamo@enea.it.
MCrAlY coating. A uniform and dense TGO, composed of pure $\alpha-\mathrm{Al}_{2} \mathrm{O}_{3}$ and with a slow growth rate, may provide further protection against oxygen propagation, thus increasing component lifetime (Ref 4).

In this context, the study of the microstructure and the mechanical properties of thermally sprayed MCrAlY coatings during short-time oxidation tests is essential in order to evaluate their oxidation resistance (Ref 5-8). For instance, Belzunce et al. (Ref 5) studied the evolution of the microhardness of CoNiCrAlY coatings after short oxidation cycles; in their work High Frequency Pulse Detonation (HFPD) was employed for fabrication purposes. In turn, the microstructural modifications induced by isothermal oxidation of High Velocity Oxy Fuel (HVOF) CoNiCrAlY coatings were investigated in Ref 6-8. In this case, it was emphasized that higher oxidation rate is observed in the first 10-20 h of thermal exposure and thus it has a strong effect on the oxidation rate of the following steady state stage. This suggests that the analysis of early stage oxidation behavior can provide meaningful information on coating performance.

In the 1990s air plasma sprayed (APS) MCrAlY coatings have been employed for environmental protection of Ni-based components such as combustors liners, gas turbines blades and vanes (Ref 9-12). However APS CoNiCrAlY coatings have generally received limited attention in recent years for higher temperature applications because an enhanced oxidation is expected when metal particles are sprayed in standard atmospheric conditions (Ref 8, 13, 14). Indeed, since 2000 the attention of the investigators has been mainly focused on more expensive and less flexible processes, such as vacuum plasma spraying (VPS) or low-pressure plasma spraying (LPPS) and HVOF spraying, respectively (Ref 4, 6-8). Compared to these thermal spraying methods, APS allows to achieve higher productivity and efficiency by a significant reduction of capital investment for equipment and time for manufacturing. So, it is much suitable for large mass production. Moreover, little work has been published about the mechanical properties of thermally sprayed CoNiCrAlY coatings (i.e., Young's modulus and 
hardness), and the data available are essentially referred to as-sprayed coatings (Ref 13-16).

Therefore, the aim of this study is to investigate the evolution of microstructural and room temperature mechanical properties of APS CoNiCrAlY coatings after early stage isothermal oxidation.

To this purpose, the phase composition and the microstructural features of the coatings were investigated by XRD and SEM, respectively. The mechanical properties of as-sprayed and oxidized coatings were in turn measured using the nanoindentation (NI) technique.

\section{Material and Methods}

\subsection{Plasma Spraying}

The powder feedstock used for coatings fabrication was a commercially available CoNiCrAlY alloy (Amdry 995C, Sulzer Metco, Westbury, NY, USA) with 38Co-32Ni-21Cr-8Al-0.5Y (wt.\%) chemical composition and a particle size distribution in the nominal range between 45 and $75 \mu \mathrm{m}$.

The coatings were deposited onto stainless steel substrates (Aisi $310 \mathrm{~S}, 25 \times 25 \times 4 \mathrm{~mm}^{3}$ ) with a nominal thickness of $150 \mu \mathrm{m}$. The APS system available at ENEA Research Centre (Brindisi, Italy), equipped with a F4-MB plasma torch (Sulzer Metco, Wolhen, Switzerland) with $6 \mathrm{~mm}$ internal diameter nozzle, was employed. Before plasma spraying, the substrates were grit-blasted using alumina abrasive powder (Metcolite F, Sulzer Metco, Westbury, NY, USA), to increase the surface roughness and to improve the mechanical interlocking at substrate/coating interface. They were placed on a rotating sample holder, while the spray gun traversed vertically. Plasma spraying parameters have been set with the purpose to guarantee a powder feed rate of about $50 \mathrm{~g} / \mathrm{min}$ and a thickness per torch pass of about $18 \mu \mathrm{m}$. The spraying parameters used in this study are summarized in Table 1.

The deposition efficiency was calculated from the ratio between the coating mass and the total feedstock mass delivered to the torch, which was determined from the powder feed rate and the spraying time on the substrate. The average deposition rate, i.e., the thickness per torch pass, was measured by a digital micrometer. It was equal to $18.1 \mu \mathrm{m}$ (standard

Table 1 Plasma spraying parameters used in this study

\begin{tabular}{ll}
\hline Parameter & Value \\
\hline Arc current, A & 600 \\
Voltage, V & 71.4 \\
Ar flow rate, slpm & 55 \\
H$_{2}$ flow rate, slpm & 11 \\
Anode-nozzle diameter, mm & 6 \\
Carrier gas flow, slpm & 3 \\
Injector diameter, mm & 1.8 \\
Injector angle, ${ }^{-}$ & 90 \\
Powder feed rate, g/min & 49.7 \\
Gun speed, mm/s & 4 \\
Turntable speed, rpm & 50 \\
Substrate tangential speed, mm/s & 1041 \\
Stand-off distance, mm & 120 \\
slpm, standard liters per minute; rpm, rotations per minute & \\
\hline
\end{tabular}

deviation $=1.4 \mu \mathrm{m})$, while the deposition efficiency was equal to $80.1 \%$ (standard deviation $=6.3 \%$ ).

After plasma spray deposition, CoNiCrAlY coatings were isothermally heat treated in air at $1110{ }^{\circ} \mathrm{C}$ for 2 and $24 \mathrm{~h}$, respectively, at a heating rate of $6^{\circ} \mathrm{C} / \mathrm{min}$, and then slowly furnace cooled down to room temperature.

\subsection{Phase Analysis and Microstructure}

The phase composition of powder feedstock, as-sprayed and oxidized coatings was analyzed using an x-ray powder diffractometer (XRD, PW 1880, Philips, Almelo, the Netherlands) with $\mathrm{CuK} \alpha(\lambda=0.154186 \mathrm{~nm})$ radiation source produced at $40 \mathrm{kV}$ and $40 \mathrm{~mA}$. The analyzed range of the diffraction angle $2 \theta$ was between $20^{\circ}$ and $90^{\circ}$, by a step width of $0.02^{\circ}$ and a time per step equal to $5 \mathrm{~s}$. XRD analysis was employed to study the phase composition of the oxide scale formed during high-temperature oxidation tests.

Feedstock morphology and coatings microstructure were analyzed by scanning electron microscopy (SEM, Gemini NVision 40, Carl Zeiss, Oberkochen, Germany) and energy dispersive X-ray spectroscopy (EDS, Oxford Instrument, Inca $\mathrm{X}$-ACT150). The cross sections of as-sprayed and annealed CoNiCrAlY coatings were cold mounted in vacuum in two-part epoxy resin and polished to $0.25 \mu \mathrm{m}$.

SEM pictures at various magnifications were processed by means of an image analysis software (Image J, U.S. National Institutes of Health, Bethesda, MD, USA), to investigate pores morphology, distribution and fraction in as-sprayed and oxidized CoNiCrAlY coatings.

\subsection{Nanoindentation}

NI is increasingly employed for measuring the mechanical properties of coatings. For instance, depth-sensing NI has been previously employed by the authors to investigate the sintering behavior of plasma sprayed zirconia-based TBCs (Ref 17, 18).

In this study, single-cycle NI tests were carried out on the cross section of as-sprayed and oxidized coatings, using a Nano-Test Platform 2 (Micro-Materials Ltd, Wrexham, UK) employing a three-sided pyramid diamond tip (Berkovich, tip radius $<100 \mathrm{~nm}$ ). For such test, selected samples were prepared using the procedure described in the previous section. The hardness and the reduced Young's modulus of the coating were determined from the analysis of the data corresponding to the unloading segment of the load-penetration curves $(P-h)$ obtained during the test; to the purpose the method proposed by Oliver and Pharr was employed (Ref 19). In particular, the hardness of the coating can be expressed as the ratio of the maximum applied load $P_{\max }$ to the projected indentation area $A_{\text {c }}$, as follows (Ref 19):

$H=\frac{P_{\text {max }}}{A_{\mathrm{c}}}$

where

$A_{\mathrm{c}}=24.5 h_{\mathrm{c}}^{2}$

in the ideal case. In our case, the diamond area function of the Berkovich indenter was calibrated by indentations to different depths into a calibration standard of fused quartz (load range 
0.5-200 mN), and was found to be $A_{\mathrm{c}}=25.2 h_{\mathrm{c}}^{2}+5779.2 h_{\mathrm{c}}$. The contact depth $h_{\mathrm{c}}$ before unloading can be estimated from the $P$ - $h$ curve using the following equation [19]:

$h_{\mathrm{c}}=h_{\max }-\varepsilon \frac{P_{\max }}{S}$

where $\varepsilon=0.75$ is a geometric constant for Berkovich tip and $S=\mathrm{d} P / \mathrm{d} h$ is the slope of the unloading curve.

Assuming that the contact area remains constant during the initial unloading, the reduced Young's modulus $E_{\mathrm{r}}$ can be expressed as follows (Ref 19):

$E_{\mathrm{r}}=\frac{1}{2 \beta h_{\mathrm{c}}} \sqrt{\frac{\pi}{A_{\mathrm{c}}}}\left(\frac{\mathrm{d} P}{\mathrm{~d} h}\right)$

with

$\frac{1}{E_{\mathrm{r}}}=\frac{1-v^{2}}{E}+\frac{1-v_{\mathrm{i}}^{2}}{E_{\mathrm{i}}}$

where $E_{\mathrm{i}}=1141 \mathrm{GPa}$ and $v_{\mathrm{i}}=0.07$ are Young's modulus and Poisson's ratio of the diamond indenter, respectively, while $\beta$ is a dimensionless parameter that varies with indenter shape $(1.012<\beta<1.034)$. The latter value has been adopted for instrumented indentation testing with Berkovich indenter in Ref 20. Multistep indentations were also performed to assess the variation of elastic modulus and hardness with the indentation load. This last was varied in the range between 100 and $500 \mathrm{mN}$, by step of $100 \mathrm{mN}$. The tests were carried out at $3.0 \mathrm{mN} / \mathrm{s}$ loading rate. The dwell time was selected to account for creep issues during the experiments. In particular, for a constant load hold period, the indentation depth may increase with time. It follows that creep effects can lead to a net increase of indentation depth during the early stages of unloading thereby affecting the elastic modulus determined using Eq 4. An extensive study on this subject was carried out in Ref 21, it was shown that the maximum load should held constant for a time interval in the range 10-60 s to make creep effects negligible. In this study a holding time of $60 \mathrm{~s}$ was then selected. An array of $5 \times 10$ indents was made for each sample tested and the results were presented using Weibull statistics.

A typical multistep NI load-depth curve is presented in Fig. 1. Note that for each cycle the unloading stage was set to

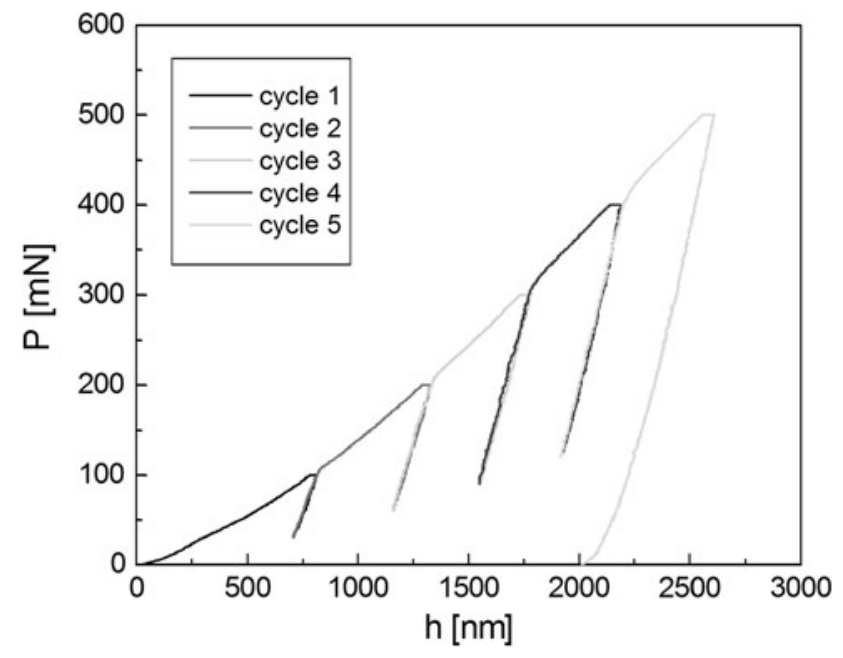

Fig. 1 Typical load-displacement $(P-h)$ curves obtained during NI tests for as-sprayed and annealed plasma sprayed CoNiCrAlY coatings
$30 \%$ of the maximum load achieved in the cycle itself. The distance between the indentations was kept equal to $30 \mu \mathrm{m}$ to avoid a mutual influence of consecutive responses.

\section{Results and Discussion}

\subsection{Phase Analysis}

As shown in Fig. 2, CoNiCrAlY alloy feedstock is composed of $\gamma-(\mathrm{Ni}, \mathrm{Co}, \mathrm{Cr})$ phase $(\Delta)$, with a smaller content of $\beta$-(Ni,Co)Al phase $(\nabla)$. The as-sprayed coating is mainly composed of $\gamma-(\mathrm{Ni}, \mathrm{Co}, \mathrm{Cr})$ phase. The intensity of $\beta$ peaks significantly decreases, suggesting a corresponding reduction in its content, while no peaks for $\alpha-\mathrm{Al}_{2} \mathrm{O}_{3}$ phase are clearly detectable in the pattern.

As shown in Fig. 2, with increasing the aging time the peak intensity for $\gamma$ phase significantly decreases, whereas a change in $\gamma / \beta$ distribution occurs (see the peaks located at $2 \theta: \sim 43.6^{\circ}$ and $\sim 44^{\circ}$, respectively). The $\beta$ phase re-appears because hightemperature oxidation decreases the thermal stresses that are responsible for its reduction during spraying, as indicated in Ref 8 .

The appearance of further peaks suggests the formation of new crystalline phases. According to Joint Committee on Powder Diffraction Standards (JCPDS) available at International Centre for Diffraction Data (ICDD), high-temperature oxidation produces the formation of several oxides, such as $\alpha-\mathrm{Al}_{2} \mathrm{O}_{3}(\boldsymbol{\nabla}), \mathrm{Cr}_{2} \mathrm{O}_{3}(*)$, and spinels ( and $\left.\boldsymbol{\bullet}\right)$. These three can be addressed to chemical reactions or diffusion phenomena occurring in the coating. Indeed, Al depletion occurs near the coating surface, while the diffusion of $\mathrm{Ni}, \mathrm{Co}$, and $\mathrm{Cr}$ through the alumina layer and their reaction with the same $\mathrm{Al}_{2} \mathrm{O}_{3}$ lead to the formation of spinel-type phases.

The peak intensity of both alumina and spinel phases increases with increasing the aging time, suggesting a gradual increase in their content on the coating surface; the spinel-type oxides are characterized by higher growth rate.

The results are in good agreement with those reported for CoNiCrAlY and NiCrAlY coatings deposited by VPS and HVOF and oxidized at 1000 and $1100{ }^{\circ} \mathrm{C}(\operatorname{Ref} 4,22)$. On the

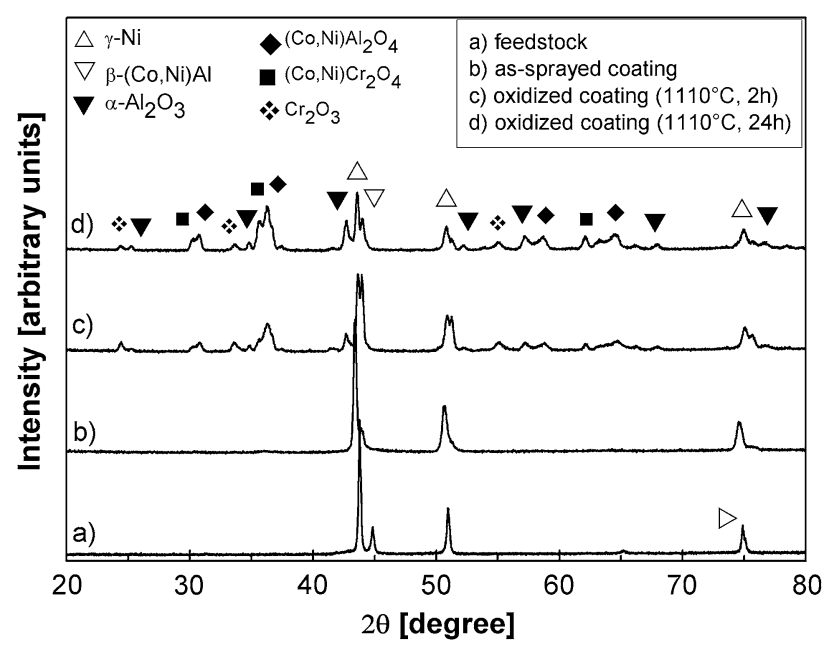

Fig. 2 XRD patterns of CoNiCrAlY powder feedstock and plasma sprayed coatings (as-sprayed and heat treated) 
other hand, Richer et al. (Ref 8) have found a significant content of $\mathrm{NiO}$ within the oxide scale in addition to spinels after $5 \mathrm{~h}$ of isothermal oxidation at $1000{ }^{\circ} \mathrm{C}$, which implies a low oxidation resistance. An enhanced oxidation has been also observed by Brandl et al. (Ref 7) for HVOF CoNiCrAlY coatings treated at $950{ }^{\circ} \mathrm{C}$ for 50 and $100 \mathrm{~h}$. The low oxidation resistance of their coatings can be explained in terms of higher degree of oxidation during processing, i.e., lower retention of un-reacted aluminum $(\operatorname{Ref} 7,8)$.

\subsection{Evolution of Coating Microstructure}

The secondary electron (SE) micrograph reported in Fig. 3 shows the morphology of gas atomized CoNiCrAlY powder, composed of spherical particles with uniform size distribution.

The cross section of APS CoNiCrAlY coating, reported in Fig. 4(a), shows a splat-like microstructure containing globular pores, splat boundaries, and oxide stringers $\left(\alpha-\mathrm{Al}_{2} \mathrm{O}_{3}\right)$ which appear as dark gray segmented streaks running approximately parallel to the splat boundaries. Several EDS maps were recorded to study the elemental composition of the coating. As shown in Fig. 4(b) the matrix is composed of various elements, such as $\mathrm{Ni}, \mathrm{Co}, \mathrm{Cr}$, and $\mathrm{Al}$, while the oxide flakes are mainly composed of $\mathrm{Al}$ and $\mathrm{O}$ even if the formation of $\mathrm{Cr}_{2} \mathrm{O}_{3}$ cannot be ruled out. However, based on further EDS analyses not reported herein for the sake of brevity, the top-surface of as-sprayed coating shows metallic characteristics with small inclusions of $\mathrm{Al}_{2} \mathrm{O}_{3}$ oxide. Indeed, the high plasma temperature and the oxidizing environment promote the partial oxidation of the exposed surface of the molten particles in the plasma jet, whereas their core does not suffer oxidation.

The dark gray regions detectable in Fig. 5 within the light gray $\gamma$ matrix are retained $\beta-(\mathrm{Ni}, \mathrm{Co}) \mathrm{Al}$ precipitates with submicrometer size. The presence of these Al-rich precipitates in large and very dense areas of the microstructure supports the low degree of oxidation of the coating and is beneficial to the coating lifetime, since these precipitates represent an aluminum reservoir for selective oxidation.

The average porosity, measured by image analysis, is $4.0 \%$ (standard deviation $=0.4 \%$ ), whereas the percentage of alumina oxides embedded in coating microstructure is approximately 2.2 (standard deviation $=0.5 \%$ ). Interestingly, these values are

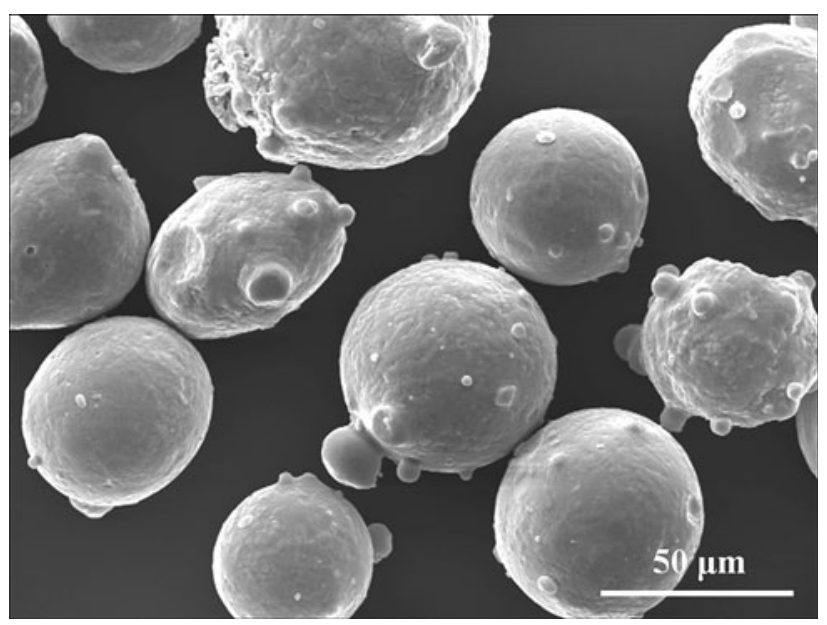

Fig. 3 SE SEM image showing the spherical morphology of gas atomized CoNiCrAlY particles lower than those obtained for several CoNiCrAlY coatings deposited by APS, LPPS, and HVOF (Ref 8, 13, 23, 24). In order to fully grasp the present results, a comparative analysis has been carried out and is summarized in Table 2. The table reports the $\%$ porosity and oxide content for CoNiCrAlY coatings deposited using different techniques: the data reported in literature have been obtained by employing Image Analysis on optical micrographs. It is worth noting that the coatings herein produced show very interesting properties (relatively low porosity and oxide content), even if denser coatings have been also obtained using optimized HVOF and HFPD methods. However, HFPD coatings could be affected by fast internal oxidation during short-time thermal cycling (about 7.5\% after a single $8 \mathrm{~h}$ cycle at $\left.960{ }^{\circ} \mathrm{C}\right)(\operatorname{Ref} 5,6)$.

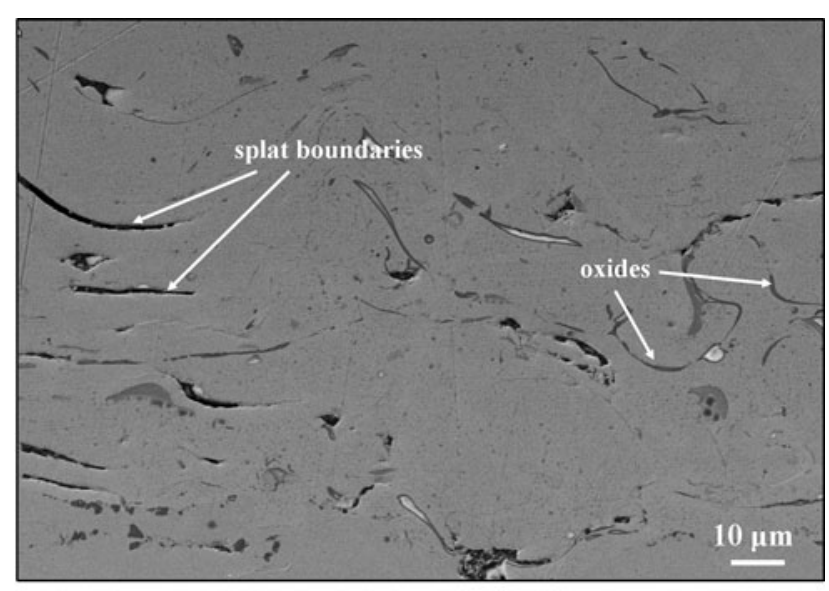

(a)

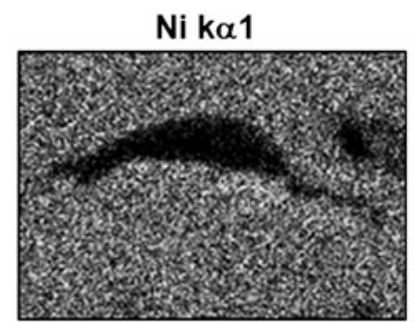

$\mathrm{Crk} \alpha 1$

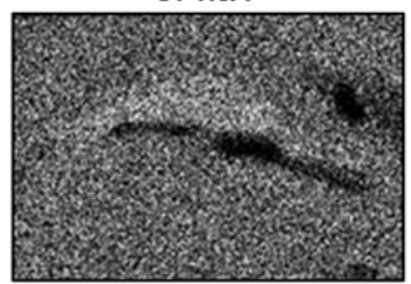

$0 \mathrm{k} \alpha 1$

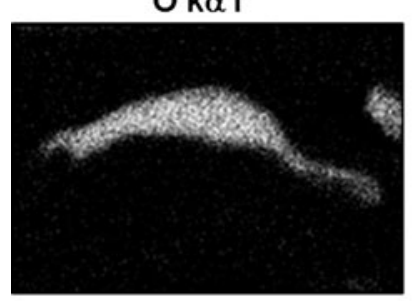

(b)

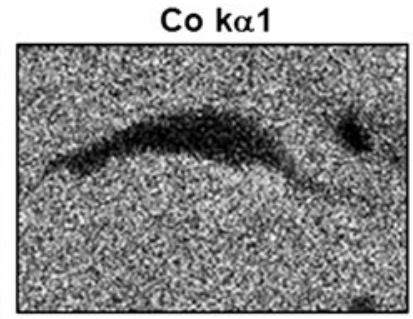

Al $k \alpha 1$
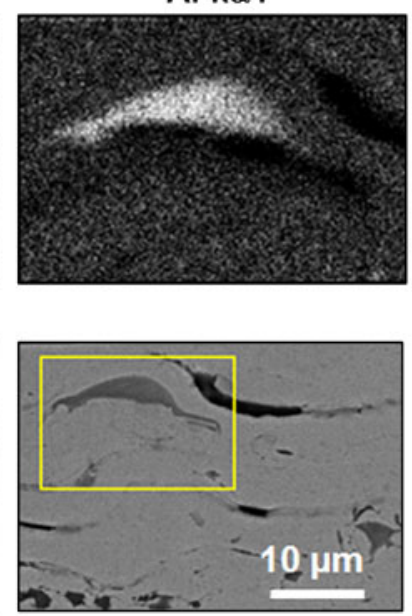

Fig. 4 (a) The microstructure of as-sprayed CoNiCrAlY coating cross section containing pores, splat boundaries, and oxide stringers. (b) EDS elemental mapping of coating cross section 


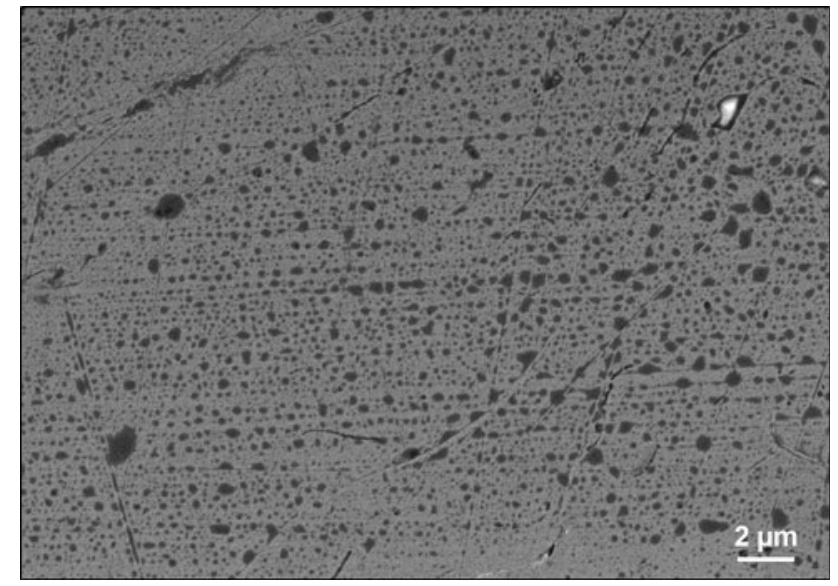

Fig. 5 Cross-sectional SEM microstructure of as-sprayed coating showing the presence of $\gamma$ matrix and $\beta$ precipitates (SE)

Table 2 Porosity and oxide content of as-sprayed CoNiCrAIY coatings

\begin{tabular}{lccc}
\hline Sample & Porosity, $\%$ & Oxide content, $\%$ & Processing \\
\hline This study & $4.0 \pm 0.4$ & $2.2 \pm 0.5$ & APS \\
Ref 8 & $5.3 \pm 0.5$ & $3.8 \pm 0.7$ & APS \\
Ref 25 & $5.1 \pm 0.7$ & $5.8 \pm 2.1$ & APS \\
Ref 25 & $4.6 \pm 1.5$ & $3.4 \pm 0.8$ & HVOF \\
Ref 26 & N.A. & $13 \pm 0.32$ & APS \\
Ref 6 & $\sim 1$ & N.A. & HVOF \\
Ref 5 & $0.8 \pm 0.2$ & $1.4 \pm 0.3$ & HFPD
\end{tabular}

N.A., not available

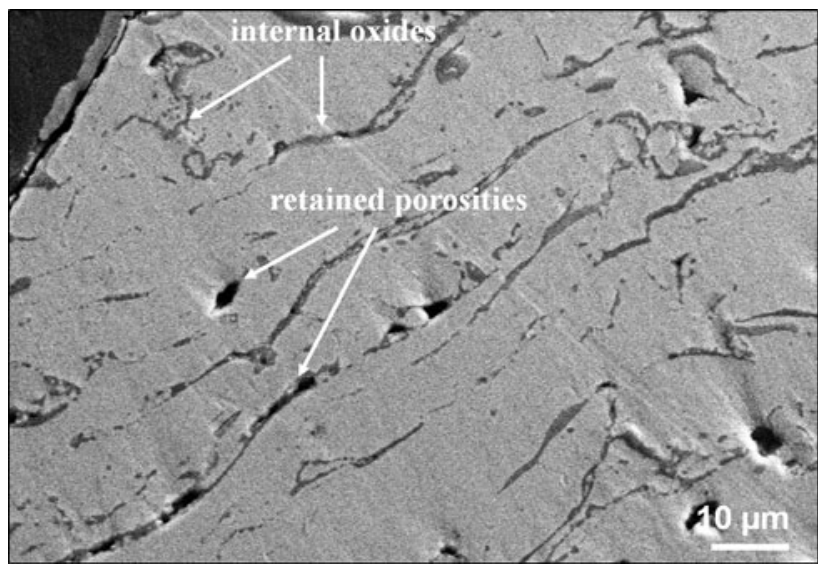

Fig. 6 SE-SEM cross-sectional microstructure of oxidized CoNiCrAlY coating $(24 \mathrm{~h})$ showing internal oxides and retained porosities. A partial densification of the same microstructure can be appreciated after oxidation tests

Figure 6 shows the cross-sectional microstructure of CoNiCrAlY coating after isothermal oxidation at $1110{ }^{\circ} \mathrm{C}$ for $24 \mathrm{~h}$. It can be seen that the partial closure of thin interfaces and fine pores promotes a partial densification of the microstructure, leading to a decrease of the total porosity, as shown in Table 3. This partial densification occurs after a very short time $(2 \mathrm{~h})$, while the amount of internal oxides slightly increases to $3.7 \%$
Table 3 Porosity and Weibull parameters for hardness and elastic modulus data of as-sprayed and oxidized CoNiCrAIY coatings

\begin{tabular}{|c|c|c|c|c|c|c|}
\hline Sample & $\begin{array}{l}\text { Porosity, } \\
\%\end{array}$ & $\begin{array}{l}\text { Oxide } \\
\text { content }\end{array}$ & H, GPa & $m_{\mathbf{H}}$ & $E_{\mathrm{v}}, \mathrm{GPa}$ & $m_{\mathbf{E r}}$ \\
\hline As-sprayed & $4.0 \pm 0.4$ & $2.2 \pm 0.5$ & 3.5 & 4.0 & 131 & 6.8 \\
\hline $\begin{array}{l}\text { Oxidized } \\
\quad\left(1110{ }^{\circ} \mathrm{C}, 2 \mathrm{~h}\right)\end{array}$ & $2.8 \pm 0.1$ & $2.9 \pm 0.6$ & 5.3 & 3.7 & 202 & 6.6 \\
\hline $\begin{array}{l}\text { Oxidized } \\
\quad\left(1110{ }^{\circ} \mathrm{C}, 24 \mathrm{~h}\right)\end{array}$ & $2.2 \pm 0.2$ & $3.7 \pm 0.5$ & 5.3 & 4.1 & 216 & 10.6 \\
\hline
\end{tabular}
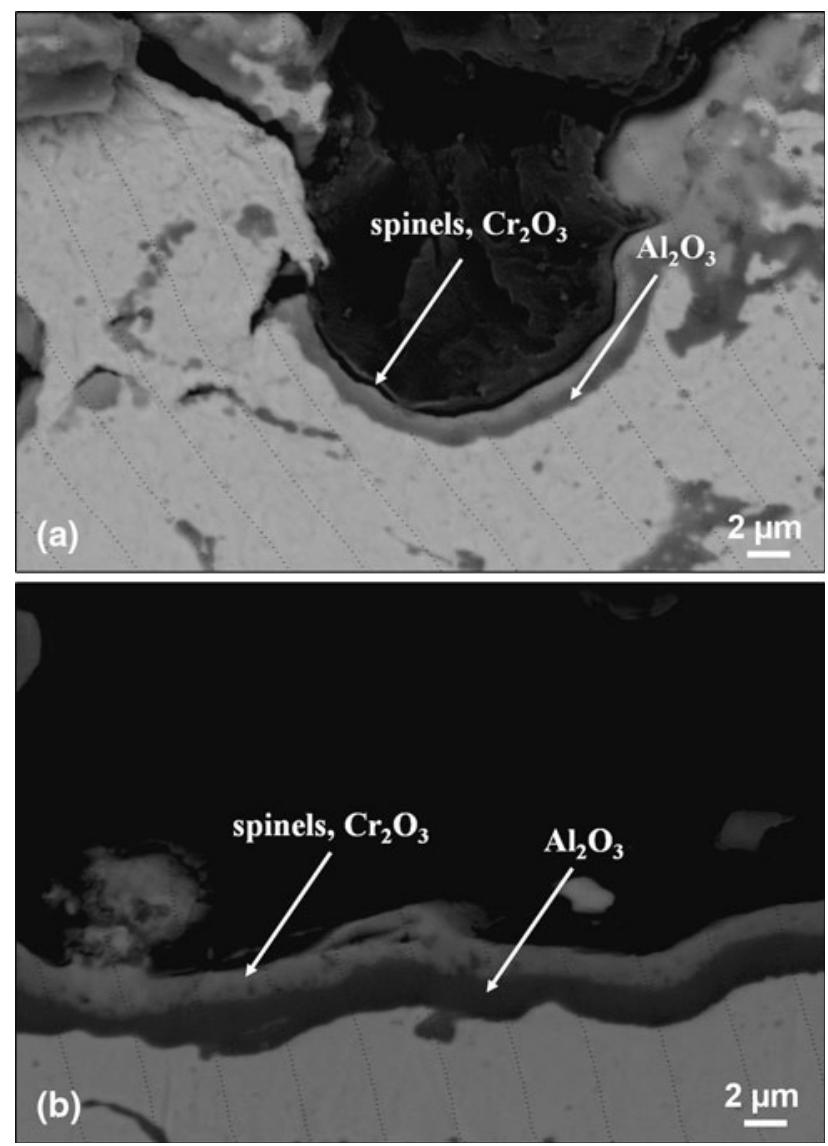

Fig. 7 BSE-SEM images showing the top-surface of oxidized CoNiCrAlY coatings: coating oxidized at $1110{ }^{\circ} \mathrm{C}$ for (a) $2 \mathrm{~h}$ and (b) $24 \mathrm{~h}$. A duplex oxide scale gradually grows with increasing the aging time

after early stage high-temperature exposure, suggesting a good resistance to oxygen penetration.

The SEM micrographs in Fig. 7 illustrate the evolution of the oxide scale on the coating top-surface after 2 and $24 \mathrm{~h}$ of isothermal exposure at $1110{ }^{\circ} \mathrm{C}$, respectively. A duplex oxide scale, composed of an inner and dense $\alpha-\mathrm{Al}_{2} \mathrm{O}_{3}$ layer (darker layer) and an upper layer composed of spinels and $\mathrm{Cr}_{2} \mathrm{O}_{3}$ (brighter layer), is observed. The upper layer is generally not uniform and has low density; moreover, it exhibits irregular protrusions. The total thickness of surface oxide layer is generally lower than $2 \mu \mathrm{m}$ after $2 \mathrm{~h}$ of isothermal exposure at $1110^{\circ} \mathrm{C}$, whereas it increases up to $3-4 \mu \mathrm{m}$ after $24 \mathrm{~h}$ (the oxide scale tends to become continuous). Therefore, a first transient 
Ni $k \alpha 1$

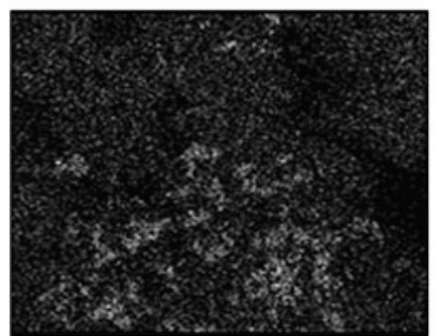

$\mathrm{Cr} k \alpha 1$

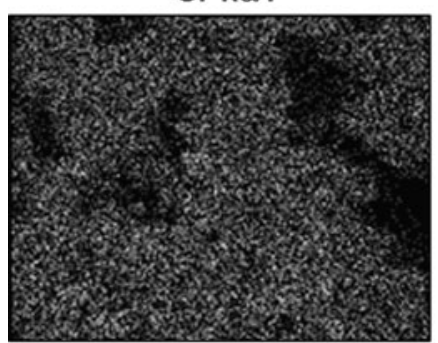

$0 \mathrm{k} \alpha 1$

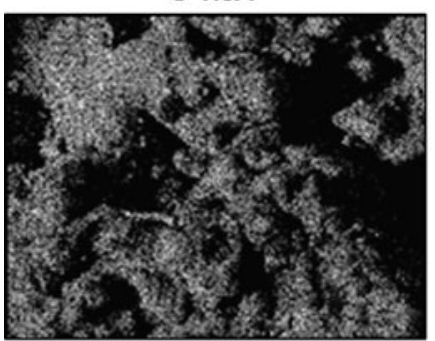

(a)
Co $k \alpha 1$

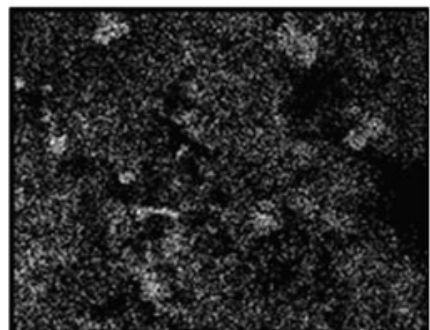

Al $k \alpha 1$
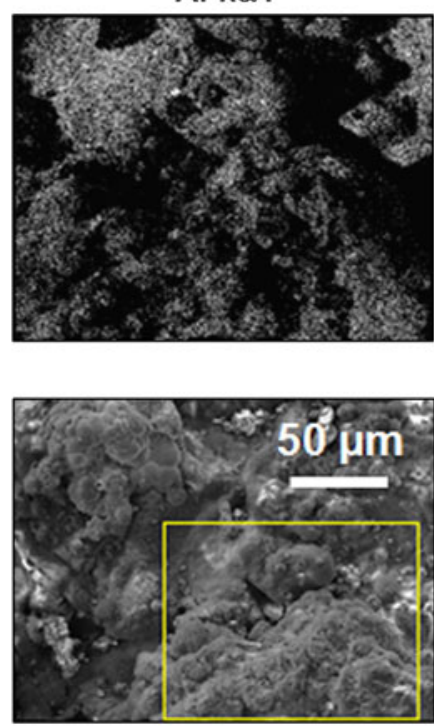

(b)
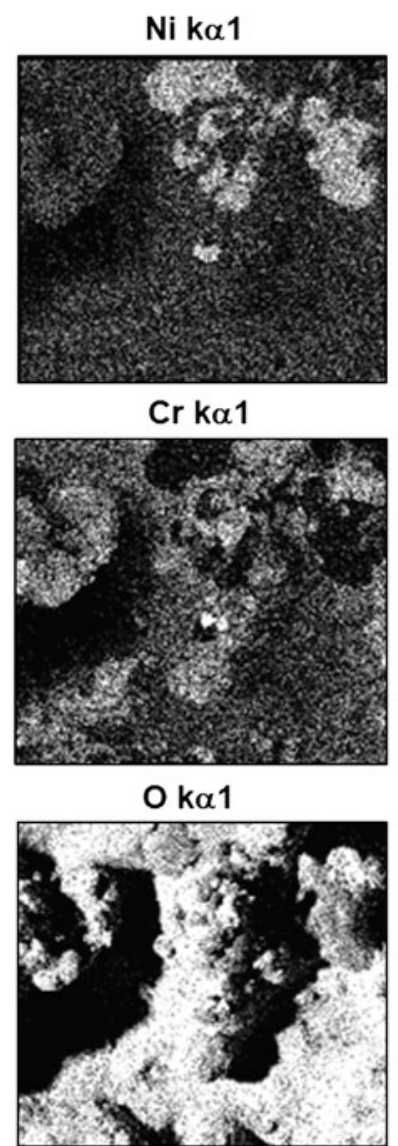

(b)

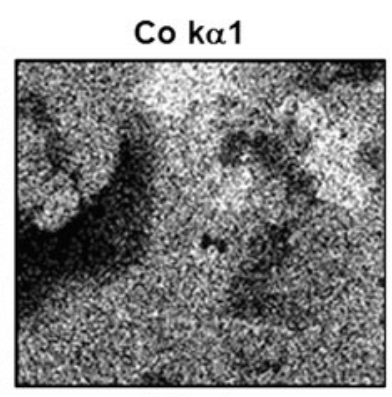

Al k $\alpha 1$
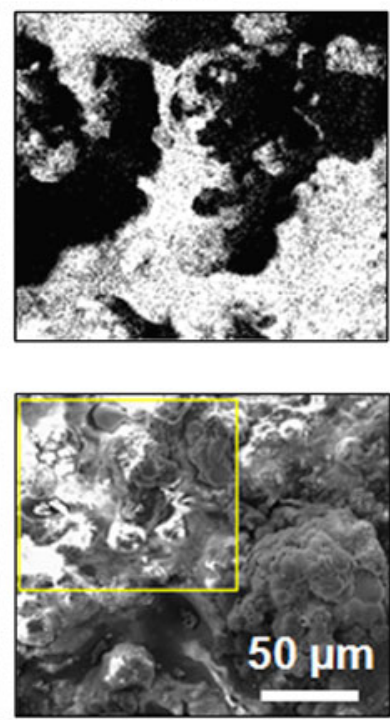

Fig. 8 SEM image showing the surface morphology and the EDS elemental mapping of the coating oxidized at $1110{ }^{\circ} \mathrm{C}$ for $24 \mathrm{~h}$

oxidation stage is followed by steady state oxidation, characterized by lower growth rate of oxide scale. The formation of spinel-type oxide scale has been also noticed for CoNiCrAlY coatings deposited by HVOF and VPS after short thermal exposures (1-24 h) at $1000-1100{ }^{\circ} \mathrm{C}(\operatorname{Ref} 25,26)$. Figure 8 shows the EDS maps of coating surface after $24 \mathrm{~h}$ of oxidation at different locations. In the area selected in Fig. 8(a) the presence of an oxide scale on the metal matrix is detectable. The EDS maps of $\mathrm{Al}$ and $\mathrm{O}$ are well matched and suggest that the oxide scale is mainly composed of $\mathrm{Al}_{2} \mathrm{O}_{3}$ with smaller contents of $\mathrm{Cr}_{2} \mathrm{O}_{3}$ and spinel-type oxides which constitute the upper scale. As shown in Fig. 8(b) the presence of spinel-type oxides containing $\mathrm{Co}, \mathrm{Ni}$, and $\mathrm{Cr}$ is more evident in the areas where Al diffusion activity is reduced. It should be noted that the EDS analysis of a rough surface typically causes shadowing effects, i.e., the appearance of dark areas due to the signal obstruction. Thereby, the elemental mapping should be considered as a qualitative analysis of the oxide scale rather than a quantitative analysis of oxides distribution.

\subsection{Room Temperature Mechanical Properties}

The results of multistep NI tests are reported in Fig. 9 and 10. Both elastic modulus and hardness decrease with increasing the maximum load. The mechanical properties (hardness and Young's modulus) decrease as the indentation load $(P)$ increases and then stabilize when $P=500 \mathrm{mN}$. We consider

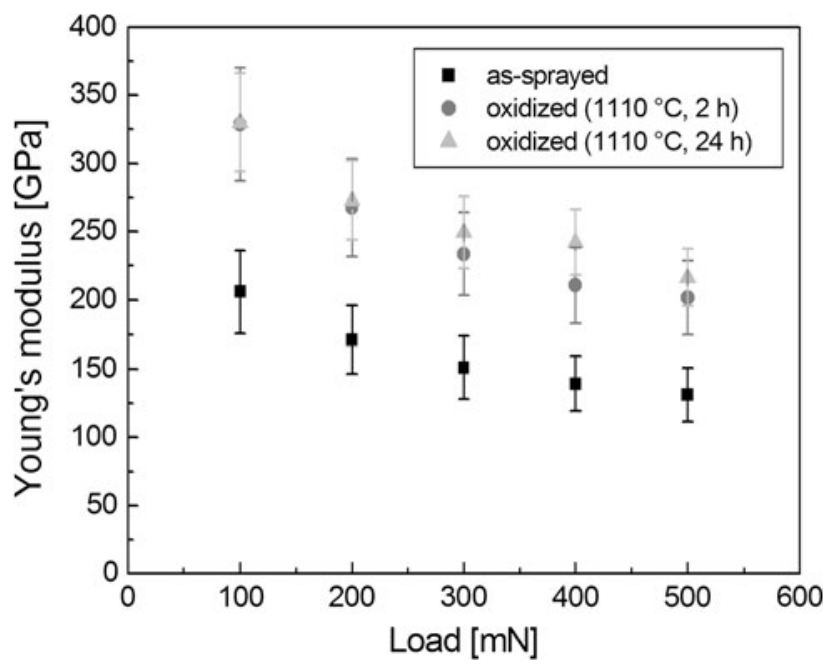

Fig. 9 Evolution of Young's modulus of CoNiCrAlY coatings as a function of the maximum indentation load

the properties corresponding to this load as representative of the mechanical behavior of the coatings.

The observed behavior may be related to the accuracy achieved in the determination of the contact area at low loads. Indeed, at lower load the contact area is usually underestimated. 


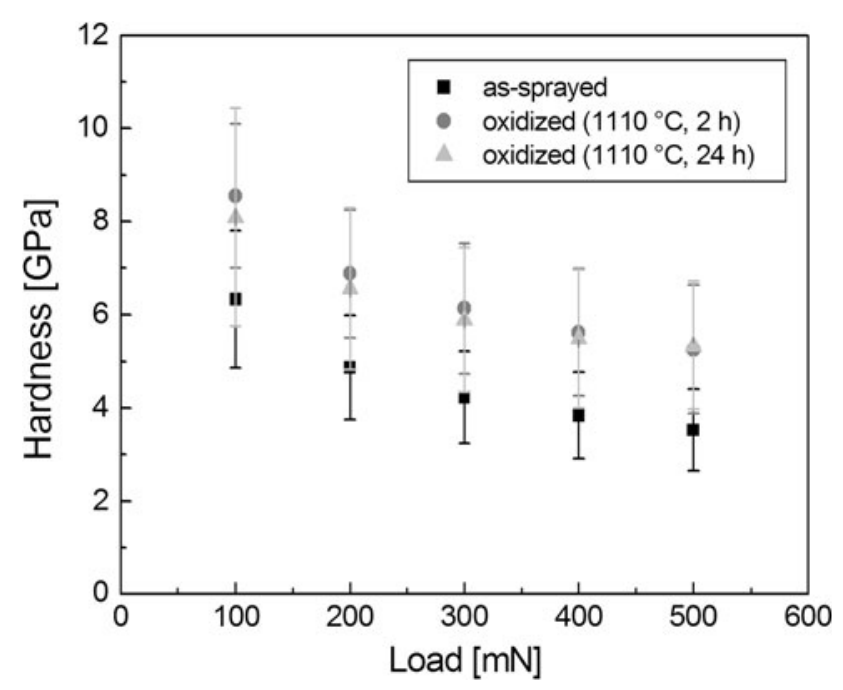

Fig. 10 Evolution of nanohardness of CoNiCrAlY coatings as a function of the maximum indentation load

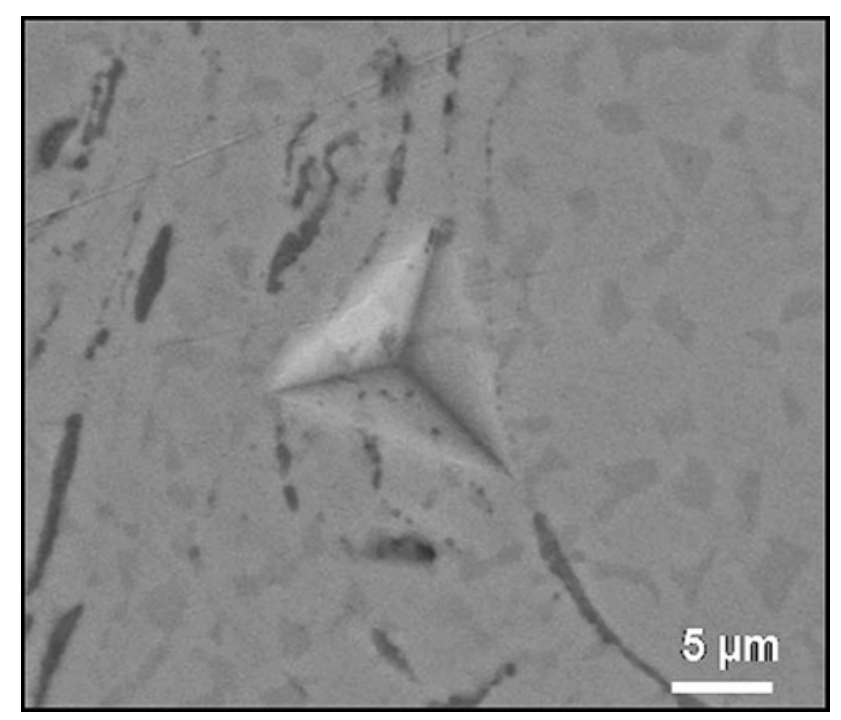

Fig. 11 SEM image showing an indent within the coating oxidized for $24 \mathrm{~h}$ at $1110^{\circ} \mathrm{C}$

Moreover, problems associated with the "pile-up" or "sink-in" of the material on the edges of the indent during the indentation process could also affect the measured values. To this purpose, SEM observations of typical indents were made and no significant pile-up or sink-in was observed (Fig. 11). Moreover, Fig. 9 and 10 confirms that Young's modulus and nanohardness increase with increasing the aging time. A sharp increase is noticed during the first hours of high-temperature exposure and then it tends to stabilize. The analysis of selected load-penetration curves, not reported herein for the sake of brevity, showed that the maximum penetration depth decreased with increasing the aging time; on the other hand, the slope of the curves tended to increase. This stiffening behavior can be attributed to the partial densification of the coating microstructure.

Figures 12 and 13 show the Weibull plots corresponding to hardness and Young's modulus data for as-sprayed and

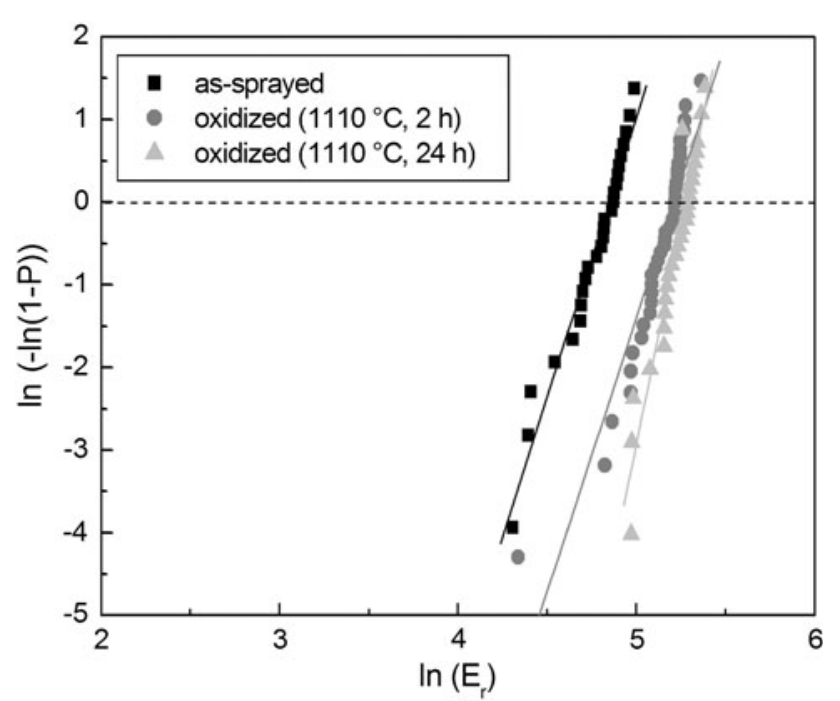

Fig. 12 Weibull plots for Young's modulus data of as-sprayed and oxidized CoNiCrAlY coatings. The Weibull curves shift toward higher Young's modulus values with increasing the aging time

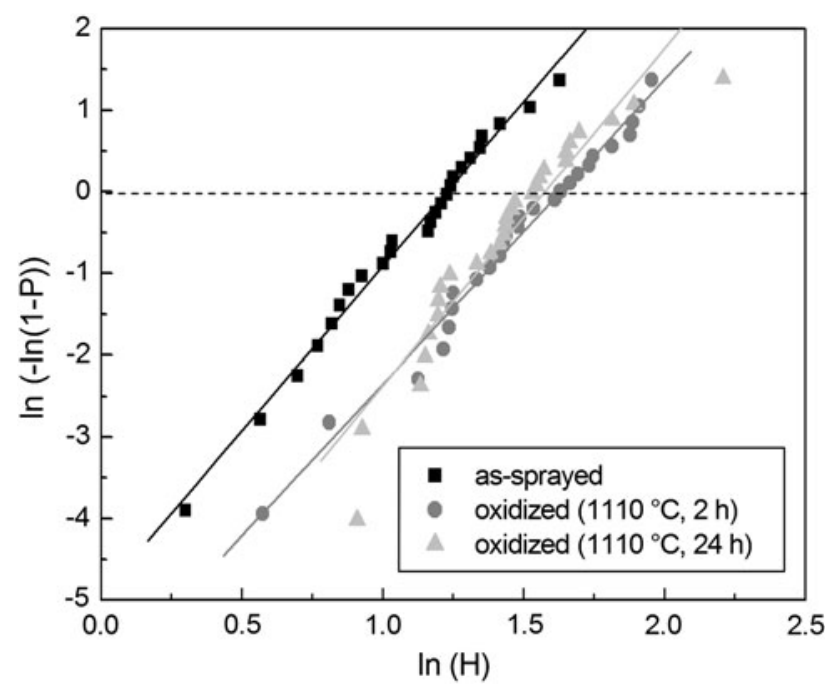

Fig. 13 Weibull plots for hardness data of as-sprayed and oxidized CoNiCrAlY coatings. The Weibull curves shift toward higher hardness values with increasing the aging time

heat-treated CoNiCrAlY coatings obtained at $500 \mathrm{mN}$ maximum indentation load.

The most meaningful data provided by the plots are the mean values of $H$ and $E_{\mathrm{r}}$ as well as the Weibull parameter, i.e., the slope $m_{\mathrm{W}}$ (Weibull modulus). The latter is directly related to the measurement scatter; in particular, steeper lines mean reduced experimental scatter. The scatter in the mechanical properties is related to the presence of fine pores embedded in the coating microstructure, as well as to the presence of interphase boundaries near the indent (Ref 27, 28).

With increasing the annealing time both hardness and elastic modulus increase, due to the partial healing of coating porosities $^{1}$ and the partial disappearance of splat boundaries, which provide a better insulation from the diffusion of oxygen

\footnotetext{
${ }^{1}$ This point can be addressed to diffusion phenomena occurring during the heat treatment.
} 
and corrosive agents from the coating surface to the substrate. The internal oxidation and the changes in $\gamma / \beta$ distribution during early stage oxidation (see Fig. 2 and the peaks located at $2 \theta$ : $\sim 43.6^{\circ}$ and $\sim 44^{\circ}$, respectively) affect the evolution of the mechanical properties to a lesser extent. As shown in Fig. 12 and 13, the Weibull curves shift towards higher values of Young's modulus and hardness. The corresponding Weibull parameters (mean value and modulus) are reported in Table 3.

The highest Weibull moduli are found for CoNiCrAlY coatings treated for $24 \mathrm{~h}$ : the denser microstructure provided reduced scatter for hardness and Young's modulus, since the effect of finer pores and splat boundaries is considerably reduced. The scatter in the data distribution can be ascribed to the retained pores as well as to the multiphase structure of the coating, i.e., the simultaneous presence of $\gamma, \beta$, and alumina phases.

The mean value of reduced Young's modulus, measured at $500 \mathrm{mN}$, is $131 \mathrm{GPa}$ for as-sprayed coating and increases up to $216 \mathrm{GPa}$ after $24 \mathrm{~h}$ at $1110{ }^{\circ} \mathrm{C}$. In turn, the average hardness is $3.5 \mathrm{GPa}$ for as-sprayed coating and increases with increasing the aging time up to $5.3 \mathrm{GPa}$ after $24 \mathrm{~h}$ at $1110^{\circ} \mathrm{C}$. The increase in Young's modulus and hardness is rather sharp; indeed, after $2 \mathrm{~h}$ at $1110^{\circ} \mathrm{C}$ the increase in Young's modulus is of about $54 \%$, while it achieves $65 \%$ after $24 \mathrm{~h}$. In turn, the increase in hardness is around $49 \%$ after $2 \mathrm{~h}$ of isothermal exposure and achieves $51 \%$ after $24 \mathrm{~h}$ of thermal aging. So, it is worth noting that a strong correlation exists between the changes occurring in the microstructure and the mechanical properties during high-temperature oxidation.

In Fig. 14, both the Young's modulus and the hardness of plasma sprayed CoNiCrAlY coatings are reported as a function of the oxidation time. The oxidation mechanism affects the mechanical properties in two stages, characterized by different oxidation rates.

Indeed, in the first hours of isothermal exposure the main microstructural modifications described in the previous section induce significant variations of the mechanical properties, i.e., a rapid increase of both hardness and elastic modulus. The rate of oxidation then decreases with increasing the aging time.

The average elastic modulus of these as-sprayed CoNiCrAlY coatings is much higher than that reported by Kwon et al. (Ref 29) for similar coatings deposited by APS (90 GPa) and

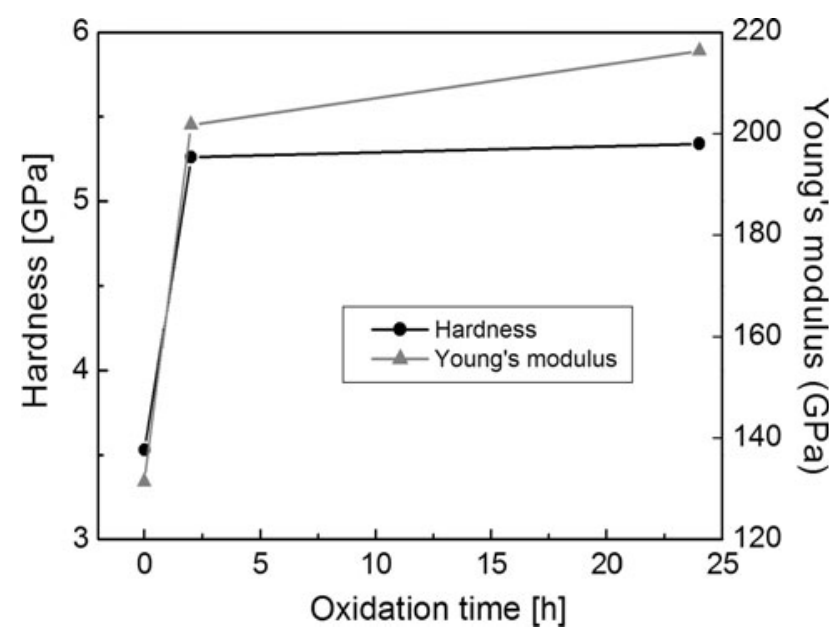

Fig. 14 The graph shows the average Young's modulus and the average hardness of CoNiCrAlY coatings as functions of the aging time. The evolution rate is higher in the first hours of heat treatment and then significantly decreases close to that found for the same coatings fabricated by HVOF $(155 \mathrm{GPa})$. In both the cases the hardness has been measured by the NI technique.

The average values of hardness reported by the same authors were 3.2 and $5.0 \mathrm{GPa}$ for coatings produced by APS and HVOF, respectively. The denser microstructure and the lowest degree of oxidation of the coatings investigated in this study explain these very promising results. Unfortunately, in the above-mentioned studies, the effect of high-temperature oxidation on the mechanical properties was not investigated and therefore a comparison was not made.

It is worth noting that Zotov et al. (Ref 30) have reported an average elastic modulus of $166 \mathrm{GPa}$ and an average nanohardness of $5.5 \mathrm{GPa}$ for CoNiCrAlY coatings deposited by electron beam physical vapor deposition (EB-PVD) and tested using a maximum indentation load equal to $100 \mathrm{mN}$. These values are lower than those obtained in this study at the same indentation load. After annealing at $1000{ }^{\circ} \mathrm{C}$ the Young's modulus of EB-PVD coatings increased up to $100 \mathrm{~h}$ and then decreased, whereas their hardness increased up to $50 \mathrm{~h}$ and then decreased. At constant oxidation time the coatings produced in this study exhibit higher Young's modulus and similar hardness than the corresponding values reported for EB-PVD coatings (Ref 30). It should be also noted that the aging tests herein discussed have been performed at higher temperature $\left(1110^{\circ} \mathrm{C}\right.$ versus $1000{ }^{\circ} \mathrm{C}$ ).

\section{Conclusions}

CoNiCrAlY coatings were deposited by atmospheric plasma spraying. Both the feedstock and the as-sprayed coating were mainly composed of $\gamma$ - $(\mathrm{Ni}, \mathrm{Co}, \mathrm{Cr})$ phase. The as-sprayed coating showed a typical splat-like microstructure with globular pores, splat boundaries, and alumina oxide stringers located along splat boundaries. The porosity fraction was equal to $4 \%$, whereas the percentage of internal oxides was $2.2 \%$ in as-sprayed state and slightly increased to $3.7 \%$ after high-temperature exposure at $1110{ }^{\circ} \mathrm{C}$. Instead, a double oxide scale gradually grew on coating top-surface and it was composed of an inner alumina layer and an upper mixed oxide layer $\left(\mathrm{Cr}_{2} \mathrm{O}_{3}+\right.$ spinels $)$. Isothermal exposure produced a partial densification of the coating microstructure, i.e., the closure of finer pores and the partial disappearance of splat boundaries, leading to a corresponding decrease of the total porosity.

The Young's modulus and the hardness of plasma sprayed CoNiCrAlY coatings, measured by the NI technique, increased with increasing the aging time, due to the coating densification and, to a lesser extent, due to the changes in internal oxidation and in $\gamma / \beta$ phase distribution.

In conclusion, APS CoNiCrAlY coatings showed interesting microstructural and mechanical properties, as well as a good resistance to early stage high-temperature oxidation. Future investigations will be devoted to studying the oxidation behavior of CoNiCrAlY coatings for longer exposure times, as well as of TBC systems, composed of bond coat and top coat.

\section{Acknowledgments}

The authors wish to thank C. Blasi (ENEA) for her valuable contribution in plasma spraying and D. Cannoletta (UNILE) for preliminary SEM observations. 


\section{References}

1. M.P. Taylor, An Oxidation Study of an MCrAlY Overlay Coating, Mater. High. Temp., 2005, 22, p 433-436

2. R. Mobarra, A.H. Jafari, and M. Karaminezhaad, Hot Corrosion Behaviour of MCrAlY Coatings on IN738LC, Surf. Coat. Technol., 2006, 201, p 2202-2207

3. W.R. Chen, X. Wu, B.R. Marple, and P.C. Patnaik, The Growth and Influence of Thermally Grown Oxide in a Thermal Barrier Coating, Surf. Coat. Technol., 2006, 201, p 1074-1079

4. S. Saeidi, K.T. Voisey, and D.G. McCartney, The Effect of Heat Treatment on the Oxidation Behavior of HVOF and VPS CoNiCrAlY Coatings, J. Therm. Spray Technol., 2009, 18(2), p 209-216

5. F.J. Belzunce, V. Higuera, and S. Poveda, High Temperature Oxidation of HFPD Thermal-Sprayed MCrAlY Coatings, Mater. Sci. Eng. A, 2001, 297, p 162-167

6. L. Zhao, M. Parco, and E. Lugscheider, High Velocity Oxy-Fuel Thermal Spraying of a NiCoCrAlY Alloy, Surf. Coat. Technol., 2004, 179, p 272-278

7. W. Brandl, G. Marginean, D. Maghet, and D. Utu, Effects of Specimen Treatment and Surface Preparation on the Isothermal Oxidation Behaviour of the HVOF-Sprayed MCrAlY Coatings, Surf. Coat. Technol, 2004, 188-189, p 20-26

8. P. Richer, M. Yandouzi, L. Beauvais, and B. Jodoin, Oxidation Behaviour of CoNiCrAlY Bond Coats Produced by Plasma, HVOF and Cold Gas Dynamic Spraying, Surf. Coat. Technol., 2010, 204, p 3962-3974

9. N.S. Bornstein, F.J. Wallace, and M.A. De Crescente, Plasma Sprayed MCrAlY Soating, US Patent 4246323, 1981

10. B.K. Gupta and T.E. Mantkowski, Thermal Barrier Coating System Having an Air Plasma Sprayed Bond Coat Incorporating a Metal Diffusion, and Method Therefor, US Patent 005817371, 1998

11. S. Li, C. Langlade, S. Fayeulle, and D. Tréheaux, Influence of the Microstructure of Plasma Deposited MCrAlY Coatings on Their Tribological Behaviour, Surf. Coat. Technol., 1998, 100-101, p 7-11

12. J. Matejicek, S. Sampath, P.C. Brand, and H.J. Prask, Quenching, Thermal and Residual Stress in Plasma Sprayed Deposits: NiCrAlY and YSZ Coatings, Acta Mater., 1999, 47, p 607-617

13. H. Waki, K. Ogura, I. Nishikawa, and A. Ohmori, Monotonic and Cyclic Deformation Behavior of Plasma-Sprayed Coatings under UniAxial Compressive Loadings, Mater, Sci. Eng. A, 2004, 374(1-2), p $129-136$

14. H. Waki and A. Kobayashi, Influence of Mechanical Properties of CoNiCrAlY Under-Coating on the High Temperature Fatigue Life of YSZ Thermal-Barrier-Coating System, Vacuum, 2008, 83(1), p 171-174

15. W.B. Choi, L. Prchlik, S. Sampath, and A. Gouldstone, Indentation of Metallic and Cermet Thermal Spray Coatings, J. Therm. Spray Technol., 2009, 18(1), p 58-64
16. T. Lauwagie, K. Lambrinou, S. Patsias, W. Heylen, and J. Vleugels, Resonant-Based Identification of the Elastic Properties of Layered Materials: Application to Air-Plasma Sprayed Thermal Barrier Coatings, $N D T \& E$ Int., 2008, 41, p 88-97

17. M. Alfano, G. Di Girolamo, L. Pagnotta, and D. Sun, Processing, Microstructure and Mechanical Properties of Air Plasma-Sprayed CeriaYttria Co-Stabilized Zirconia Coatings, Strain, 2010, 46, p 409-418

18. M. Alfano, G. Di Girolamo, L. Pagnotta, D. Sun, J. Zekonyte R.J.K. Wood, The Influence of High-Temperature Sintering on Microstructure and Mechanical Properties of Free-Standing APS CeO2-Y2O3-ZrO2 Coatings, J. Mater. Sci., 2010, 45, p 2662-2669

19. W.C. Oliver and G.M. Pharr, An Improved Technique for Determining Hardness and Elastic Modulus using Load and Displacement Sensing Indentation Experiments, J. Mater. Res., 1992, 7, p 1564-1583

20. W.C. Oliver and G.M. Pharr, Measurement of Hardness and Elastic Modulus by Instrumental Indentation: Advances in Understanding and Refinements to Methodology, J. Mater. Res., 2004, 19, p 3-20

21. T. Chudoba and F. Richter, Investigation of Creep Behaviour under Load during Indentation Experiments and its Influence on Hardness and Modulus Results, Surf. Coat. Technol., 2001, 148(2-3), p 191-198

22. C.H. Lee, H.K. Kim, H.S. Choi, and H.S. Ahn, Phase Transformation and Bond Coat Oxidation Behavior of Plasma-Sprayed Zirconia Thermal Barrier Coatings, Surf. Coat. Technol., 2000, 124, p 1-12

23. V. Higuera, F.J. Belzunce, and J. Riba, Influence of the Thermal-Spray Procedure on the Properties of a CoNiCrAlY Coating, Surf. Coat. Technol., 2006, 200, p 5550-5556

24. T. Patterson, A. Leon, B. Jayaraj, J. Liu, and Y.H. Sohn, Thermal Cyclic Lifetime and Oxidation Behavior of Air Plasma Sprayed CoNiCrAlY Bond Coats for Thermal Barrier Coatings, Surf. Coat. Technol., 2008, 203, p 437-441

25. P. Poza and P.S. Grant, Microstructure Evolution of Vacuum Plasma Sprayed CoNiCrAlY Coatings after Heat Treatment and Isothermal Oxidation, Surf. Coat. Technol., 2006, 201, p 2887-2896

26. F. Tang, L. Ajdelsztajn, G.E. Kim, V. Provenzano, and J.M. Schoenung, Effects of Surface Oxidation during HVOF Processing on the Primary Stage Oxidation of a CoNiCrAlY Coating, Surf. Coat. Technol., 2004, 185, p 228-233

27. Z. Wang, A. Kulkarni, S. Deshpande, T. Nakamura, and H. Herman, Effects of Pores and Interfaces on Effective Properties of Plasma Sprayed Zirconia Coating, Acta Mater., 2003, 51, p 5319-5334

28. T. Nakamura, G. Qian, and C.C. Berndt, Effects of Pores on Mechanical Properties of Plasma-Sprayed Ceramic Coatings, J. Am. Ceram. Soc., 2000, 83(3), p 578-584

29. J.Y. Kwon, J.H. Lee, Y.G. Jung, and U. Paik, Effect of Bond Coat Nature and Thickness on Mechanical Characteristic and Contact Damage of Zirconia-Based Thermal Barrier Coatings, Surf. Coat. Technol., 2006, 201, p 3483-3490

30. N. Zotov, M. Bartsch, and G. Eggeler, Thermal Barrier Coating Systems-Analysis of Nanoindentation Curves, Surf. Coat. Technol., 2009, 203, p 2064-2072 